\title{
Factors Associated with Antenatal Care Services Utilization and Institutional deliveries
}

\author{
Dr. Kusum Lata Gaur ${ }^{1}$, Dr. Prerna Gupt ${ }^{2}$, Dr. Rajveer Kuldeep ${ }^{3}$, Dr. Mahesh C. \\ Sharma $^{4}$, Dr. Rashmi Gupta ${ }^{5}$ Dr. R. K. Manohar ${ }^{6}$ \\ 1,2,5,6 (Department of PSM, SMS. Medical College, Jaipur (Rajasthan) India) \\ ${ }^{4}$ (PMO, R.K. Joshi District Hospital Dausa (Rajasthan) India) \\ ${ }^{3}$ (Department of Respiratory Medicine,J.L.N. Medical College,Ajmer (Rajasthan) India)
}

\begin{abstract}
:
Background: Pregnancy related deaths were avoidable if all women would have access to effective reproductive health services so utilization of Ante natal care (ANC) and Intra-natal care services is necessary to decreased maternal and infant mortality.

Objective: To find out the factors associated with utilization of ANC and Institutional deliveries. Materials and Methods: A community based cross sectional descriptive type of observational study was carried out in the field practice area of RHTC Naila in Jaipur district of Rajasthan. 30 Cluster sampling technique was used to cover whole field practice area of RHTC. 450 mothers having children $<1$ year in the selected clusters were interviewed. Information about the ANC services utilization and relevant socio-demographic data were collected. To find out associating factors appropriate tests of significance were used.

Results: ANC utilization was observed 94\% but adequate ANC utilization was only in 13.5\%. Mother's age, religion and socioeconomic status were not associated (P.0.05) with ANC services utilization whereas mother's age at effective marriage $(p<0.001)$, age at $1^{\text {st }}$ delivery $(p=0.002)$, education $(p<0.001)$, occupation $(p=0.020)$, obstetrical history $(p<0.001)$, caste $(p=0.004)$, type of families $(p<0.001)$ and family size $(p<0.001)$ were associated with ANC services utilization. Institutional deliveries were (INC) observed $99.56 \%$. Institutional deliveries were is associated with ANC utilization.
\end{abstract}

Conclusions: Factors associated with ANC utilization were mother's age at effective marriage, age at $1^{\text {st }}$ delivery, education, occupation, obstetrical history, caste, type of families and family size

Key words: ANC, INC, Institutional deliveries, Obstetrical history

\section{Introduction}

World Health Organization (WHO) ${ }^{1}$ estimates suggested that 88 to 98 percent of all pregnancy related deaths. These deaths were avoidable if all women would have access to effective reproductive health services. ${ }^{2}$ Therefore, utilization of Ante natal care (ANC) and Intra-natal care services is necessary to decreased maternal and Infant mortality. Objective of these services is to monitor pregnant women regularly during their pregnancy, so that the risk factor can be identified.

Two of the key MDG goals ${ }^{4}$ i.e. Reduction of childhood mortality and improving Maternal health, are related with ANC and INC services utilization. Antenatal care coverage of the world is $72 \%$, industrialized countries $98 \%$, developing country $28 \%$ (WHO, 2003). ${ }^{3}$ Maternal mortality in India is 254 per 100,000 live births ${ }^{5}$ and the state of Rajasthan contributes significantly to India's burden of maternal deaths.

If the factors associated with ANC and INC services utilization will be known, it will facilitate to increases coverage of these services which intern can reduce infant and maternal mortality. So this present study was undertaken to find out the factors associated with ANC utilization and Institutional Deliveries.

\section{Materials And Methods}

A community based cross sectional descriptive type of observational study was carried out in the field practice area of RHTC Naila attached to department of Community Medicine, SMS Medical College, Jaipur. 30 Cluster sampling technique was used to cover whole field practice area of RHTC. Data collection for this study was carried out from $1^{\text {st }}$ Aug 2012 to $31^{\text {st }}$ Dec 2012.

Calculation of sample size: Sample size was calculated 374 subjects at allowable error of $20 \%$ at $95 \%$ confidence interval and design effect of two assuming $35.24 \%$ non utilization of ANC services ( i.e. $\mathbf{P}=\mathbf{3 5 . 2 4 \%}$ ).

Sample size $=4 \mathrm{PQ} / \mathrm{L} 2$, here $Q=100-P=64.76 \%, L=$ Error $(20 \%$ of $P)=7 \%$

Therefore, $4 * 35.24 * 64.76 / 7 * 7=187$ but Design effect $=2$ so $\mathrm{SS}=187 * \mathrm{DE}=187 * 2=374$ 
So for the study purpose, 15 mothers from each clusters i.e. total 450 mothers of children $<1$ years residing $\geq$ one year and willing to participate were surveyed from 30 clusters All the mothers were interviewed using a predesigned, pretested, semi-structured interview schedule. Relevant information about the ANC services utilization was recorded along with the socio-demographic data. Information was cross-checked with the available records to minimize the recall bias.

Data thus collected was entered into Microsoft excel 2010 worksheet in the form of master chart. Then data were classified and analyzed as per the aims and objectives with help of appropriate statistical software. Chi-square test was used wherever necessary.

\section{Results}

In the present study, out of total 450 mothers 421 i.e. $93.56 \%$ had utilized ANC services and only 65 i.e. $15.44 \%$ of mothers were given home visits. Likewise 448 i.e. $99.56 \%$ were institutional deliveries.

This study also observed that age, religion and socioeconomic status of mothers were not associated with ANC services utilization whereas mother's caste, type of families and family size were associated with ANC services utilization. It was also observed that mothers of SC category, nuclear families and family size upto 5 were having more chances for not utilizing ANC services than others in that category.

It was also revealed that education and occupation of mothers were associated with utilization of ANC services. All the women, who had not utilized ANC services, were illiterates and doing Arri-Tari/embroidy work in their houses.

Present study shows that mean age of mother and mean age at marriage of mothers were not associated with ANC services utilization whereas mother's age at menarche, age at effective marriage and age at $1^{\text {st }}$ delivery were significantly $(\mathrm{P}<0.05)$ more in mothers utilizing ANC services. It was also observed that although parity of mothers was not associated with ANC utilization but mean difference in gravidity and parity was significantly $(\mathrm{P}<0.001)$ more in mothers utilizing ANC services. It also observed that regularity and blood flow in menstrual cycle were not associated with ANC services utilization whereas mother's age at menarche was associated with ANC services utilization. It was observed that those mothers who were not utilizing ANC services had significantly $(\mathrm{P}<0.05)$ lower age at menarche. Like wise it was also observed that all the mothers who were not utilizing ANC services were those who have identified their pregnancies themselves.

It was also revealed in this study that out of total 29 mothers who have not utilized ANC services, majority (19 i.e. $65.52 \%$ ) of mothers quoted tradition as a cause for not utilizing ANC services whereas (11 i.e. $37.93 \%$ ) of mothers were telling that they had no problem during this and last pregnancies.

Regarding intra-natal care services utilization it was observed in the present study that out of total 448 mothers who had utilized ANC services, majority (>95\%) of mothers had feeling of safety and timely treatment of any risk during delivery in hospital whereas 236 mothers had adopted hospital delivery because they can get vaccination $(52.68 \%)$ of their child in times. This table also shows that few mothers $(0.22$ to $6.7 \%)$ said that Dai was not available, they already has LSCS delivery, they can get easy reference etc.

It was also observed shows regarding intra-natal care services utilization that out of total 421 mothers who had utilized ANC services, majority $(72.45 \%$ to $84.32 \%$ ) of mothers had feeling of safety and timely treatment of any risk during pregnancy in utilizing ANC services whereas 104 and 68 of mothers were using ANC services because they can get vaccination $(24.7 \%)$ and investigations $(7.13 \%)$ needed in times but 68 $(16.15 \%)$ of mothers said that Dai was not available so they came to health institute. And those 2 mothers who have not adopted institutional deliveries, both the mothers quoted tradition as a cause behind not adopting institutional deliveries whereas one mother added that transport was not available.

Pie Diagramme of ANC Services Utilization

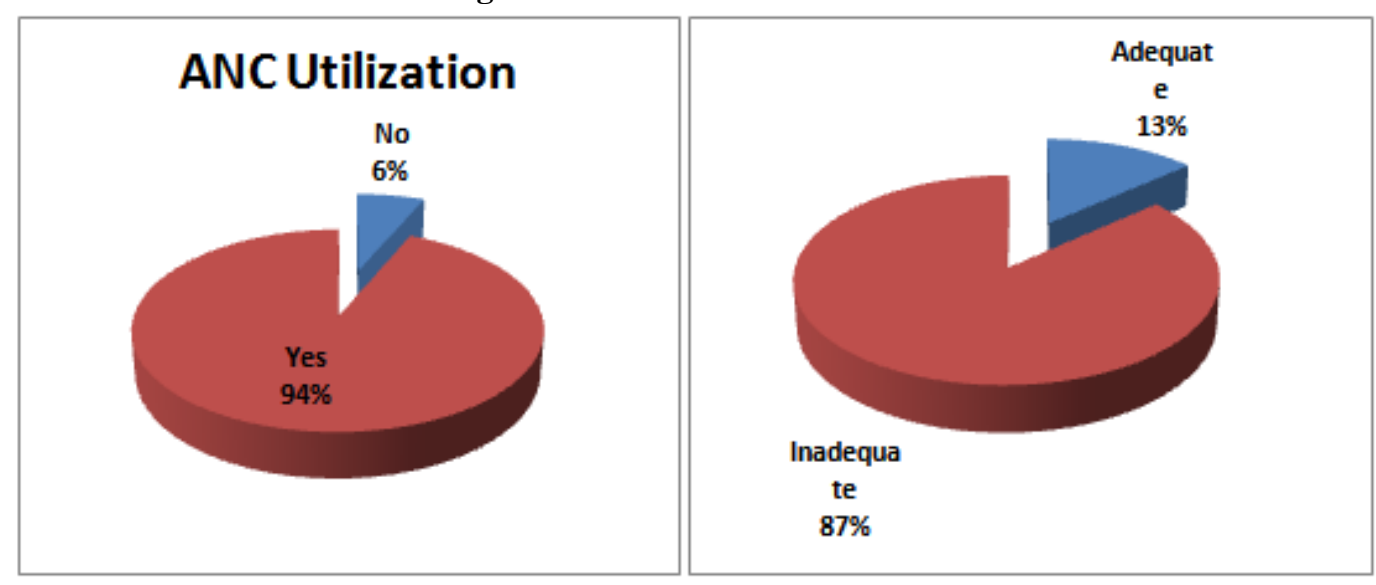


Pie Diagramme of Intra-natal Services Utilization

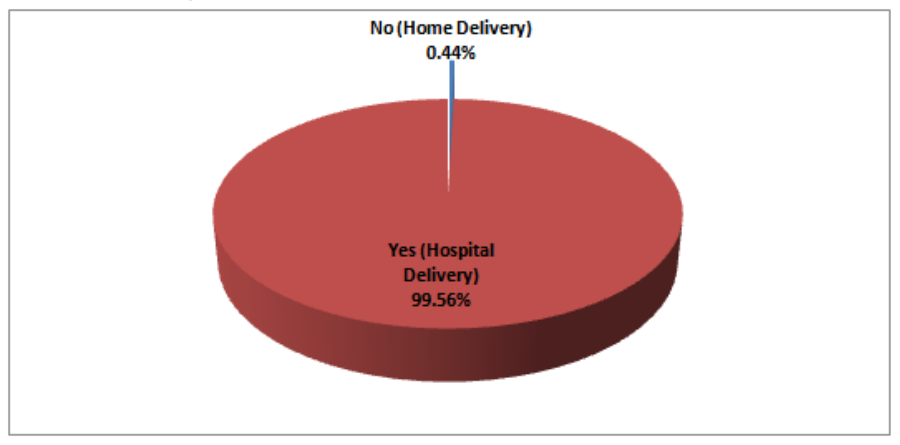

Association of ANC Utilization with Education and Occupation

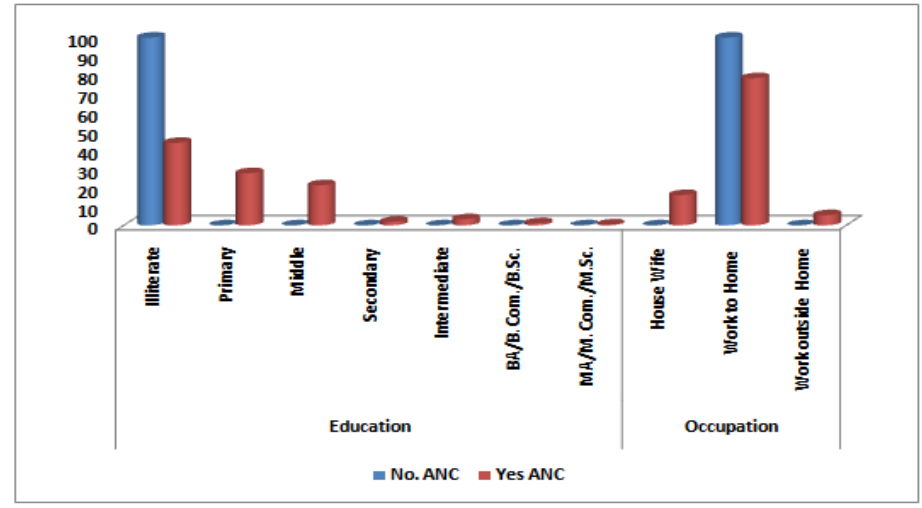

Table No. 1

Association of ANC Utilization with Socio-demographic Variables

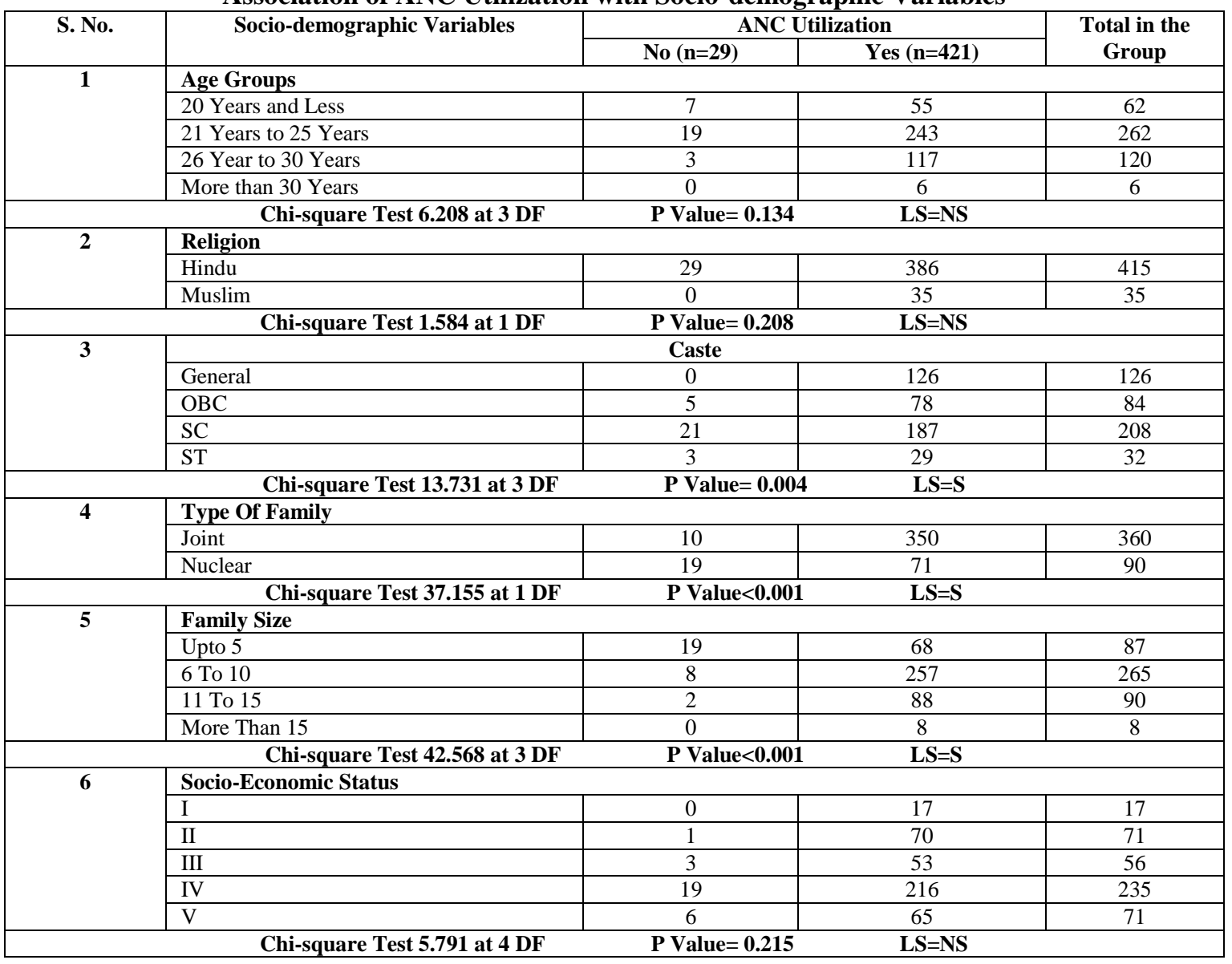


Table No. 2

Association of ANC Utilization with factors related to Reproductive life

\begin{tabular}{|c|c|c|c|c|c|}
\hline \multirow[t]{2}{*}{ S. No. } & \multirow{2}{*}{$\begin{array}{c}\text { Variables } \\
\text { at the time of Survey }\end{array}$} & \multicolumn{2}{|c|}{ ANC Utilization } & \multirow{2}{*}{\multicolumn{2}{|c|}{$\begin{array}{c}\text { Unpaired 't' Test } \\
\text { at } 448 \mathrm{DF}\end{array}$}} \\
\hline & & No $(n=29)$ & Yes $(n=421)$ & & F LS \\
\hline \multirow[t]{2}{*}{1} & & & & \multicolumn{2}{|c|}{-1.226} \\
\hline & Age of Beneficiary (Yrs) & $23.59 \pm 2.03$ & $24.21 \pm 2.67$ & 0.221 & NS \\
\hline \multirow[t]{2}{*}{2} & & & & \multicolumn{2}{|c|}{-2.406} \\
\hline & Age at Menarche (Yrs) & $13.63 \pm 0.67$ & $13.93 \pm 0.13$ & 0.017 & $\mathbf{S}$ \\
\hline \multirow[t]{2}{*}{3} & & & & \multicolumn{2}{|c|}{-1.969} \\
\hline & Age at Marriage (Yrs) & $15.93 \pm 2.90$ & $16.85 \pm 2.40$ & 0.050 & NS \\
\hline 4 & $\begin{array}{l}\text { Age at Effective Marriage } \\
\text { (Yrs) }\end{array}$ & $16.67 \pm 2.09$ & $18.06 \pm 1.53$ & \multicolumn{2}{|c|}{-4.609} \\
\hline 5 & Age at $1^{\text {st }}$ Delivery (Yrs) & $19.07 \pm 1.73$ & $19.96 \pm 1.44$ & \multicolumn{2}{|c|}{-3.176} \\
\hline 6 & Gravida & $2.28 \pm 0.51$ & $2.81 \pm 1.26$ & \multicolumn{2}{|c|}{-2.251} \\
\hline 7 & Para & $2.17 \pm 0.34$ & $2.16 \pm 0.83$ & \multicolumn{2}{|c|}{-0.640} \\
\hline 8 & $\begin{array}{l}\text { Mean difference Gravida and } \\
\text { Para }\end{array}$ & $0.11 \pm 0.03$ & $0.65 \pm 0.12$ & \multicolumn{2}{|c|}{-24.258} \\
\hline 9 & Abortions & 0 & $0.52 \pm 0.67$ & $\mathbf{N}$ & \\
\hline 10 & Still Birth & 0 & $0.10 \pm 0.17$ & $\mathbf{N}$ & \\
\hline
\end{tabular}

Table No. 3

Association of ANC Utilization with factors related to Obstetrical History

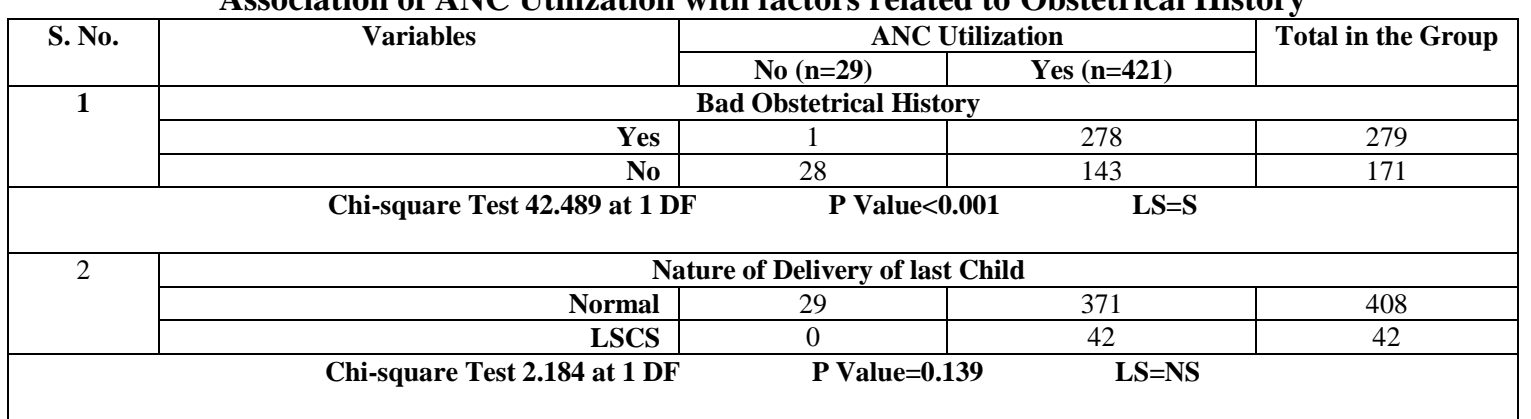

Table No. 4

Status of Association of various factors with ANC Utilization

\begin{tabular}{|c|c|c|c|c|}
\hline S. N. & Factors & $\mathrm{P}$ value & $\mathrm{LS}$ & Status of Association \\
\hline 1. & Age of Beneficiary & 0.134 & NS & Not Associated \\
\hline 2. & Religion & 0.208 & NS & Not Associated \\
\hline 3. & Caste & 0.004 & $\mathrm{~S}$ & Associated \\
\hline 4. & Type of Family & $<0.001$ & $\mathrm{~S}$ & Associated \\
\hline 5. & Family Size & $<0.001$ & $\mathrm{~S}$ & Associated \\
\hline 6. & Socio-economic Status & 0.215 & NS & Not Associated \\
\hline 7. & Education of Mother & $<0.001$ & $\mathrm{~S}$ & Associated \\
\hline 8. & Occupation of Mother & 0.020 & $\mathrm{~S}$ & Associated \\
\hline 9. & Age at Menarche & 0.017 & $\mathrm{~S}$ & Associated \\
\hline 10. & Regularity of M. Cycle & 0.153 & NS & Not Associated \\
\hline 11. & Blood Flow in M. Cycle & 0.220 & NS & Not Associated \\
\hline 12. & Age at Marriage & 0.050 & NS & Not Associated \\
\hline 13. & Age at Effective Marriage & $<0.001$ & $\mathrm{~S}$ & Associated \\
\hline 14. & Age at $1^{\text {st }}$ Delivery & 0.002 & $\mathrm{~S}$ & Associated \\
\hline 15. & Nature of delivery of last child & 0.139 & NS & Not Associated \\
\hline 16. & $\mathrm{Bad} \mathrm{OH}$ & $<0.001$ & $\mathrm{~S}$ & Associated \\
\hline
\end{tabular}

Table No. 5

Strength of Association of various factors with ANC Utilization

\begin{tabular}{|c|l|c|c|c|c|c|}
\hline S. No. & \multicolumn{1}{|c|}{$*$ Factors } & OR & $95 \%$ CL & Chi-square & P value & LS \\
\hline 1. & Age (21-25 Years) & 1.392 & $0.632-3.066$ & 0.359 & 0.529 & NS \\
\hline 3. & Caste (SC) & 3.285 & $1.423-7.584$ & 7.465 & 0.004 & S \\
\hline 4. & Type of Family(Nuclear) & 9.366 & $4.179-20.994$ & 37.155 & $<0.001$ & S \\
\hline 5. & Family Size(upto 5) & 9.863 & $4.394-22.139$ & 39.288 & $<0.001$ & S \\
\hline 6. & SES (IV Class) & 1.803 & $0.819-3.970$ & 1.663 & 0.197 & NS \\
\hline 7. & Age at Menarche(12-13 Yrs) & 3.191 & $1.382-7.368$ & 7.051 & 0.008 & S \\
\hline 8. & Bad OH & 54.434 & $7.331-404.174$ & 42.489 & $<0.001$ & S \\
\hline
\end{tabular}




\section{Discussion}

In the present study age, religion and socioeconomic status of mothers were not associated with ANC services utilization whereas mother's education, occupation, caste, type of families and family size were associated with ANC services utilization. It was also observed that mothers of SC category, nuclear families and family size upto 5 were having more chances for not utilizing ANC services than others in that category. Likewise, mother's age at menarche, age at effective marriage and age at $1^{\text {st }}$ delivery were associated with ANC services $(\mathrm{P}<0.05)$ whereas age at marriage, regularity and amount of blood flow were not associated. Although nature of last delivery was not associated with ANC utilization but obstetrical history had an association.

Many of the authors have reported almost similar observations that socio-demographic factors were associated with both ANC and institutional delivery attendance. ${ }^{6,7,8,9,10,11,12}$

National Family Health Survey 3 (NFHS-3) ${ }^{6}$ indicated that more ANC utilization was observed in younger women than older ones, educated than illiterates and primi-gravida than multi-gravida. Study made in Ghana on economic factors affecting the demand for ANC reported that living standard \& education of women have significant impact on the demand and sufficiency of $\mathrm{ANCs}^{8}$ Demographic characteristics of women like age and parity predict more closely the use of ANC services than pregnancy intention in Bihar and Jharkhand. Delayed ANC initiation may be significantly associated with unwanted pregnancy. ${ }^{9}$ In another study ${ }^{10}$ multivariate regression analysis revealed that maternal age \& women's education were the important determinants of ANC services utilization.

A study conducted in Manipal, Karnataka, India by Chandrashekhar $\mathrm{S}^{11}$ identified the factors which determine the utilization of ANC were maternal literacy, occupation, age and parity.

In contrast to present study observations, some other author ${ }^{12}$ observed that cost influenced their antenatal attendance

However, to identify and removal of constraint of underutilization of ANC and INC services, number of ANC visits and overall utilization with institutional deliveries, the maternal mortality and pregnancy wastage can be reduced.

\section{Conclusion}

Mother's age, religion and socioeconomic status were not associated with ANC services utilization whereas mother's age at effective marriage, age at $1^{\text {st }}$ delivery, education, occupation, obstetrical history, caste, type of families and family size were associated with ANC services utilization. INC utilization is associated with ANC utilization.

\section{References}

[1]. WHO, UNICEF, UNFPA. Maternal mortality in 2000: Estimates developed by WHO, UNICEF, UNFPA. Geneva: WHO; 2003.

[2]. Kunst, A.E and T.Houweling. 2001. A global picture of poor-rich differences in the utilization of delivery care in safe motherhood strategies. A review of the evidence 17: ITG Press, Belgium, 297-315.

[3]. McDonagh, M. 1996. Is ANC effective in reducing maternal morbidity and mortality? Health Policy Planning 11: 1-15.

[4]. http://www.who.int/reproductivehealth/publications/maternal_perinatal_health/effective_antenatal_care.pdf

[5]. WHO. 1996. Coverage of prenatal care: A listing of available information. Fourth edition, (WHO/FRH/MSM 196.28), Geneva

[6]. International Institute for Population Sciences (IIPS) and Macro International. 2007. National Family Health Survey (NFHS-3), 2005-06: India: Volume II. Mumbai: IIPS

[7]. Singh A, Arora A K. The changing profile of pregnant women and quality of antenatal care in rural North India. Indian J Community Med 2007; 32:135-6

[8]. Overbosch, G. B., Nsowah-Nuamah, N. N. N., Van den Boom, G. J. M., \&Damnyag, L. (2004). Determinants of antenatal care use in Ghana. Journal of African Economies, 13(2), 277-301.

[9]. Barrick L, Koenig MAPregnancy intention and antenatal care use in two rural north Indian States. World Health Popul. 2008;10(4):21-37

[10]. Kamal SM, Hassan CH, Islam MN Factors Associated With the Timing of Antenatal Care Seekingin Bangladesh. Asia Pac J Public Health. 2013 Oct 4.

[11]. Chandrashekar S, Rao RS, Nair NS, Kutty PRSocio-demographic determinants of antenatal care. Trop Doct. 1998 Oct;28(4):206-9.

[12]. Asundep NN, Carson AP, Turpin CA, Tameru B, Agidi AT, Zhang K, Jolly PE Determinants of access to antenatal care and birth outcomes in Kumasi, Ghana. J Epidemiol Glob Health. 2013 Dec; 3(4):279-88. doi: 10.1016/j.jegh.2013.09.004. Epub 2013 Oct 10 